\title{
The Role that Electrolytes Play in the Synthesis of Water-Soluble CdTe Quantum Dots Prepared at Ambient Temperature
}

\author{
Melissa S. Carvalho, ${ }^{a}$ Caroline Mayrinck, ${ }^{a}$ Ellen Raphael, ${ }^{a}$ Jefferson Bettini, ${ }^{b, \#}$ \\ Jefferson L. Ferrari ${ }^{a}$ and Marco A. Schiavon*,a
}

\author{
${ }^{a}$ Grupo de Pesquisa em Química de Materiais (GPQM), Departamento de Ciências Naturais, \\ Universidade Federal de São João del-Rei, Campus Dom Bosco, Praça Dom Helvécio, 74, \\ 36301-160 São João del-Rei-MG, Brazil
}

${ }^{b}$ Laboratório Nacional de Nanotecnologia, Centro Nacional de Pesquisa em Energia e Materiais, 13083-970 Campinas-SP, Brazil

\begin{abstract}
In this work, we have synthesized CdTe quantum dots (QDs) dispersed in an aqueous medium at ambient temperature, and investigated their optical properties. Synthesis of CdTe QDs in the presence of simple amines removed the need for an additional energy source and inert atmosphere, in a simple and inexpensive experimental setup. The use of ammonia or hydrazine promoted nanoparticle growth by kinetic nanocrystal agglomeration in the initial growth stage. These weak electrolytes acted in the electrical double layer during the growth of the nanocrystals. A comparative study on the concentration of hydrazine in the reaction medium helped to investigate their role in nanocrystal growth. Substitution of hydrazine for ethylenediamine and other electrolytes like sodium chloride and ammonium chloride contributed to a better understanding of the mechanism that underlies the use of primary amines in the synthesis of CdTe. The synthesis conditions afforded the highest photoluminescence quantum yield for CdTe QDs prepared at room temperature (27.5\%).
\end{abstract}

Keywords: optical properties, semiconductors, chemical synthesis, luminescence, nucleation

\section{Introduction}

Nanocrystalline semiconductors with diameters smaller than the Bohr exciton radius of the material are called quantum dots (QDs). The physical properties of QDs depend heavily on nanocrystal size. ${ }^{1,2}$ The first syntheses of these materials date back to the 1980s. ${ }^{3}$ QDs possess unique properties that distinguish them from other materials; e.g., nanocrystal size-dependent photoluminescence (PL) emission, narrow emission and absorption bands, elevated PL quantum yields, high PL intensity, good chemical stability, and resistance to photodegradation. ${ }^{4}$ These characteristics make QDs applicable in an ever-growing number of fields, ${ }^{5}$ such as technological areas, including solar cells, ${ }^{5-7}$ LEDs, ${ }^{8,9}$ photocatalytic processes, ${ }^{10,11}$ and biomedical systems. ${ }^{12}$ QDs can conjugate with biomolecules. Indeed, QDs have found application as biological markers in biomedical assays and in vivo

*e-mail: schiavon@ufsj.edu.br

\#Current address: Department of Materials, University of Oxford, Parks Rd, Oxford OX1 3PH, England. imaging, ${ }^{12-17}$ and as biosensors and sensors to detect small molecules and proteins. ${ }^{18,19}$

A variety of experimental techniques are available to synthesize QDs, but the colloidal chemistry route stands out, this route affords matrix-free QDs and enables control of nanocrystal size, shape, and functional chemical surface. ${ }^{20,21}$ According to the Lamer diagram, two main interdependent events underlie nanocrystal formation via the colloidal route: nucleation and growth. ${ }^{22}$ Such events may stem from agglomeration of small clusters by means of kinetic processes and/or thermodynamically favored diffusion of monomers, as described by the classic colloid growth theory. 22,23

The colloidal chemistry method is flexible: it produces QDs in solvents with high boiling point, as in the case of organometallic synthesis, ${ }^{24-26}$ or at $100{ }^{\circ} \mathrm{C}$, in aqueous medium at normal pressure. ${ }^{21,27}$ Although both methods have intrinsic advantages and disadvantages, ${ }^{21,24-27}$ authors have favored the synthesis of QDs in aqueous medium. While the organometallic route relies on toxic, expensive, pyrophosphoric precursors that demand high 
reaction temperatures, the reaction in aqueous medium is cheaper and less toxic, requires lower temperature, and uses an eco-friendly solvent (green chemistry concept). The synthesis of QDs in an aqueous medium employs mercapto compounds, which reduce surface defects and enhance growth dynamics. ${ }^{28-31} \mathrm{~A}$ number of alternative methodologies have emerged in an attempt to improve the quality of nanocrystals grown in aqueous solvent; e.g., hydrothermal synthesis, microwave irradiation, and sonochemistry. ${ }^{32-35}$

The synthesis of CdTe QDs in aqueous medium generally involves $(i)$ chemical reduction of tellurium powder in the presence of sodium borohydride $\left(\mathrm{NaBH}_{4}\right)$, at $80{ }^{\circ} \mathrm{C}$, to give NaHTe, ${ }^{28}$ and (ii) preparation of a precursor cadmium ion solution by dissolution of a cadmium salt and the desired surface ligand. It is necessary to adjust the solution $\mathrm{pH}$ to high values and to stir the solution under an inert atmosphere. The authors have successfully used this approach to synthesize QDs, obtaining PL quantum yields as high as $80 \% .^{28}$ Nevertheless, this strategy includes variables that are difficult to control and reproduce, such as tellurium oxidation. In fact, $\mathrm{Te}^{2-}$ ions are unstable and reactive in aqueous medium; in the presence of small amounts of oxygen, these anions spontaneously oxidize to elemental tellurium and other reduced forms. ${ }^{36}$ In addition, heating decomposes the mercapto ligands and releases sulfur into the reaction medium, which possibly diminishes the quantum yield of QDs and leads to loss of ligand functionality. ${ }^{28,37}$

To simplify procedures and make them less toxic, researchers have modified the routes that afford QDs. An important alteration has been to prepare water-soluble QDs at ambient temperature. In 2009, Yang and co-workers ${ }^{37}$ reported a new synthetic route in aqueous medium and inert atmosphere to obtain CdTe QDs. In 2011, the same group produced CdTe QDs via one-pot synthesis that employed ambient conditions and direct addition of reactants into a single Erlenmeyer flask, which removed the use of inert atmosphere, $\mathrm{pH}$ adjustment, and reagents' preparation and purification. ${ }^{38,39}$ The latter synthesis occurred in the presence of weak electrolytes like simple amines. These amines weakened the electrostatic repulsion between particles, competed with the surface ligand for coordination with cadmium, accelerated nanocrystal growth, and facilitated agglomeration of precursor ions. ${ }^{37-40}$ In 2015 , Tan et al. ${ }^{41}$ reported a facile synthesis of CdTe-based QDs promoted by mercaptosuccinic acid and hydrazine.

This work reports an improvement on the understanding of the synthesis of CdTe QDs at ambient conditions, in the presence of a simple amine (hydrazine or ethylenediamine) and other electrolytes such as $\mathrm{NaCl}$ and $\mathrm{NH}_{4} \mathrm{Cl}$. We have chosen 3-mercaptopropionic acid (MPA) as the surface ligand because this is the most used surface ligand in the preparation of water-soluble QDs. We have determined that the simple amines promoted nanoparticle growth by kinetic agglomeration of the nanocrystals during the initial growth phase. A comparative study of hydrazine concentration in the reaction medium aided investigation of the role played by simple amines. Substitution of hydrazine for ethylenediamine and other electrolytes such as sodium chloride and ammonium chloride provided a better understanding of how primary amines influenced the mechanism for the low-cost CdTe synthesis.

\section{Experimental}

\section{Materials}

Sodium tellurite $\left(\mathrm{Na}_{2} \mathrm{TeO}_{3}, 99 \%\right)$, sodium borohydride $\left(\mathrm{NaBH}_{4}, 99 \%\right)$, 3-mercaptopropionic acid (MPA, 99\%), rhodamine $101\left(\mathrm{C}_{32} \mathrm{H}_{30} \mathrm{~N}_{2} \mathrm{O}_{3}, 100 \%\right)$, and ethylenediamine $\left(\mathrm{NH}_{2} \mathrm{CH}_{2} \mathrm{CH}_{2} \mathrm{NH}_{2}, 99 \%\right)$ were purchased from SigmaAldrich (St. Louis, USA). Cadmium(II) chloride $\left(\mathrm{CdCl}_{2} \cdot \mathrm{H}_{2} \mathrm{O}\right.$, $99 \%)$ and hydrazine hydrate $\left(\mathrm{N}_{2} \mathrm{H}_{4} \cdot \mathrm{H}_{2} \mathrm{O}, 80 \%\right.$ in water $)$ were acquired from Vetec (Rio de Janeiro, Brazil) and Merck (Kenilworth, USA), respectively. Ammonium chloride $\left(\mathrm{NH}_{4} \mathrm{Cl}, 99.5 \%\right)$ was obtained from Synth (Diadema, Brazil). Sodium hypochlorite $(\mathrm{NaOCl})$, as commercial bleach, and sodium chloride ( $\mathrm{NaCl})$, as commercial cooking salt, were supplied by Santa Clara (Contagem-MG, Brazil) and Sal Marlim (Cabo Frio, Brazil), respectively. Type I water (electric conductivity lower than $0.1 \mu \mathrm{S} \mathrm{cm}$ ) was employed during the synthesis of QDs.

\section{Preparation of the solution of CdTe QDs}

CdTe QDs were prepared by direct addition of the reactants in an open flask. Briefly, $0.010 \mathrm{mmol}$ of $\mathrm{CdCl}_{2}$. $\mathrm{H}_{2} \mathrm{O}$ were dissolved in $10.5 \mathrm{~mL}$ of deionized water. Then, $0.02 \mathrm{mmol}$ of MPA, $0.002 \mathrm{mmol}$ of $\mathrm{Na}_{2} \mathrm{TeO}_{3}, \mathrm{NaBH}_{4}$, and $\mathrm{N}_{2} \mathrm{H}_{4} \cdot \mathrm{H}_{2} \mathrm{O}$ were added. The order of addition of reagents was very important to obtain CdTe QDs. The reduction of $\mathrm{Na}_{2} \mathrm{TeO}_{3}$ to $\mathrm{Te}^{2-}$ ions by $\mathrm{NaBH}_{4}$ was accomplished in one hour. Then, $\mathrm{N}_{2} \mathrm{H}_{4} \cdot \mathrm{H}_{2} \mathrm{O}$ was added and the time of the reaction initialized. The solution was kept at ambient temperature and pressure, and no $\mathrm{pH}$ adjustment was made. Because of the basicity of hydrazine, the $\mathrm{pH}$ of the solution was extremely high ( $\mathrm{pH}$ above 12). The concentration of $\mathrm{NaBH}_{4}$ and added $\mathrm{N}_{2} \mathrm{H}_{4} \cdot \mathrm{H}_{2} \mathrm{O}$, was varied according to Table 1. QDs were precipitated by addition of isopropanol, which was followed by centrifugation. CdTe QDs were also obtained in a similar way using ammonia, ethylenediamine, 
and other electrolytes such as sodium chloride and ammonium chloride instead of hydrazine.

Table 1. Concentrations of $\mathrm{NaBH}_{4}$ and $\mathrm{N}_{2} \mathrm{H}_{4} \cdot \mathrm{H}_{2} \mathrm{O}$ used in the synthesis of CdTe QDs

\begin{tabular}{lcc}
\hline Condition & $\mathrm{NaBH}_{4} /\left(\mathrm{mg} \mathrm{mL}^{-1}\right)$ & $\mathrm{N}_{2} \mathrm{H}_{4} /\left(\mathrm{mol} \mathrm{L}^{-1}\right)$ \\
\hline 1 & 2.500 & 5.0 \\
2 & 1.250 & 8.8 \\
3 & 0.025 & 10.0 \\
4 & 0.015 & 15.0 \\
\hline
\end{tabular}

\section{Characterization of CdTe QDs}

UV-Vis absorption spectra were recorded on a Shimadzu spectrophotometer, model UV-2550. PL spectra were registered on a Shimadzu spectrofluorimeter, model RF-5301PC, equipped with a 150-W xenon lamp; samples were excited at $355 \mathrm{~nm}$. Luminescence lifetimes were measured on a Horiba fluorimeter, model TCSPC. Addition of NanoLED NLC-2 for measurements on a nanoscale allowed analysis of lifetimes. Nanosecond pulses generated by a NanoLED emitting at $455 \mathrm{~nm}$ were used to excite the samples; the repetition rate was $1 \mathrm{MHz}$. To record UV-Vis and PL spectra and lifetimes, the QDs were dispersed in Hellma quartz cuvettes with an optical path length of $1.0 \mathrm{~cm}$. X-ray diffraction (XRD) patterns were acquired on a Shimadzu diffractometer, model XRD-6000, with $\mathrm{CuK} \alpha$ radiation $(\lambda=1.541838 \mathrm{~nm})$. Scanning and transmission electron microscopy (STEM) images were obtained using a JEM 2100 FEG-TEM microscope operating at $200 \mathrm{kV}$. The QD dispersions were deposited on 300-mesh copper grids containing an ultrathin carbon film. After deposition, the grids were repeatedly immersed in isopropanol. Zeta potentials were measured on a particle size and zeta potential analyzer (Delsa Nano, Beckman Coulter). Aqueous dispersions of the QDs were analyzed at $\mathrm{pH}$ ca. 8. The equipment software used a Smoluchowski approximation to calculate the zeta potential values. Because of the sensitivity of zeta potential measurements, each sample was analyzed in triplicate; the final result corresponds to the average of the three measurements. The PL quantum yield $\left(\theta_{\mathrm{f}}\right)$ of the QDs was based on a comparative method designed by Williams et al. ${ }^{42}$ Rhodamine $101\left(\theta_{\mathrm{f}}=1.0\right)$ was used as the standard solution. All of the measurements were performed at ambient temperature and conditions.

\section{Environmental treatment of hydrazine}

Because hydrazine is toxic, all of the samples containing this amine underwent treatment to ensure their safe discharge into the environment. Among the methods available to treat hydrazine, hydrazine decomposition with ozone, oxygen (electrolysis), hydrogen peroxide, or sodium hypochlorite stand out. This work employed hydrazine decomposition with sodium hypochlorite, which is an efficient and inexpensive method. To this end, sodium hypochlorite solution was added to the hydrazine solutions dropwise, until all of the hydrazine was consumed. Next, the solutions were acidified with sulfuric acid, so that they would have an appropriate $\mathrm{pH}$, between 5 and 9 , for discharge. ${ }^{43,44}$

\section{Results and Discussion}

\section{Synthesis of CdTe QDs in the presence of hydrazine}

Reactions 1 to 3 illustrate the process used to obtain the MPA-CdTe QDs. First, $\mathrm{CdCl}_{2}$ was dissolved in water. Next, the reagents MPA, $\mathrm{Na}_{2} \mathrm{TeO}_{3}, \mathrm{NaBH}_{4}$, and $\mathrm{N}_{2} \mathrm{H}_{4} \cdot \mathrm{H}_{2} \mathrm{O}$ were added. This order ensured formation of $\mathrm{Cd}^{2+}$ ion complexes with MPA (reaction 1), the $\mathrm{p} K_{\mathrm{a}}$ of MPA is 4.34 , followed by reduction of tellurite ions by $\mathrm{NaBH}_{4}$ (reaction 2). Then, reaction of telluride ions with $\mathrm{Cd}^{2+}$ coordinated with MPA afforded the MPA-CdTe QDs (reaction 3):

$$
\begin{aligned}
& \mathrm{Cd}_{(\mathrm{aq})}^{2+}+\mathrm{MPA}_{(\mathrm{aq})} \leftrightarrow \mathrm{MPA}-\mathrm{Cd}_{(\mathrm{aq})}^{2+} \\
& 4 \mathrm{TeO}_{3(\mathrm{aq})}^{2-}+3 \mathrm{BH}_{4(\mathrm{aq})}^{--} \leftrightarrow 4 \mathrm{Te}_{(\mathrm{aq})}^{2-}+3 \mathrm{BO}_{2(\mathrm{aq})}^{-}+6 \mathrm{H}_{2} \mathrm{O}_{(\mathrm{l})} \\
& \mathrm{xMPA}-\mathrm{Cd}_{(\mathrm{aq})}^{2+}+\mathrm{Te}_{(\mathrm{aq})}^{2-} \leftrightarrow(\mathrm{CdTe})-(\mathrm{MPA})_{\mathrm{x}(\mathrm{s})}
\end{aligned}
$$

The resulting mixture was maintained under ambient conditions. The addition of MPA prior to the addition of $\mathrm{Na}_{2} \mathrm{TeO}_{3}$ ensured that MPA coordinated to $\mathrm{Cd}^{2+}$ and prevented $\mathrm{Na}_{2} \mathrm{TeO}_{3}$ hydrolysis to $\mathrm{CdTeO}_{3}$ and/or $\mathrm{Cd}(\mathrm{OH})_{2} \cdot{ }^{45}$ Both $\mathrm{NaBH}_{4}$ and $\mathrm{N}_{2} \mathrm{H}_{4} \cdot \mathrm{H}_{2} \mathrm{O}$ can act as reducers. Here, $\mathrm{NaBH}_{4}$ was added first, due to different reducibility and reaction rates. $\mathrm{NaBH}_{4}$ reduced $\mathrm{Na}_{2} \mathrm{TeO}_{3}$ to $\mathrm{Te}^{2-}$. Only then $\mathrm{N}_{2} \mathrm{H}_{4} \cdot \mathrm{H}_{2} \mathrm{O}$ was added, to avoid $\mathrm{Te}^{2-}$ oxidation in the reaction medium. ${ }^{38}$

Figure 1 shows the UV-Vis and PL absorption spectra of the MPA-CdTe QDs in the absence (Figures 1a and 1b) and presence (Figures 1c and 1d) of $\mathrm{N}_{2} \mathrm{H}_{4} \cdot \mathrm{H}_{2} \mathrm{O}$. In the absence of the amine, the UV-Vis absorption bands did not shift to higher wavelengths, nor was the displacement of the PL bands significant. Besides that, the broad PL bands in Figure 1b had a full width at half maximum of around $140 \mathrm{~nm}$, and the bands overlapped, indicating that nanocrystals did not grow and that growth during the synthesis was not ordered. In contrast, in the presence of $\mathrm{N}_{2} \mathrm{H}_{4} \cdot \mathrm{H}_{2} \mathrm{O}$, the UV-Vis absorption bands shifted to higher wavelength during the synthesis (from 

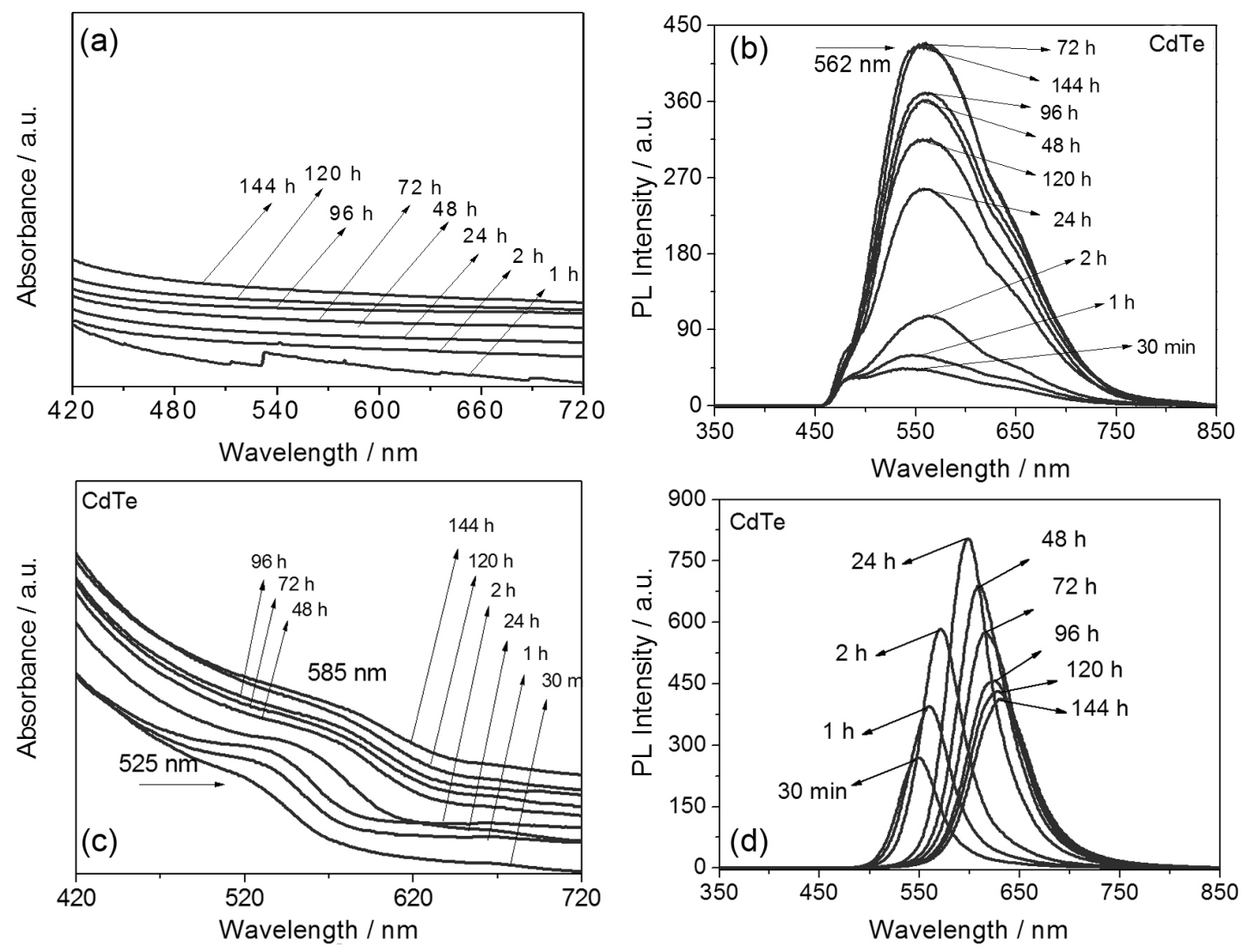

Figure 1. UV-Vis and PL spectra of the MPA-CdTe QDs synthesized in the (a, b) absence and (c, d) presence of $\mathrm{N}_{2} \mathrm{H}_{4} \cdot \mathrm{H}_{2} \mathrm{O}$ at 5.0 mol L-1. The excitation wavelength for the PL spectra was $355 \mathrm{~nm}$.

525 to $585 \mathrm{~nm}$, Figure 1c). In the same way, the emission bands shifted toward the red (from 548 to $636 \mathrm{~nm}$, Figure 1d). These results suggested that the nanocrystal size increased during the synthesis, and that $\mathrm{N}_{2} \mathrm{H}_{4} \cdot \mathrm{H}_{2} \mathrm{O}$ played a significant part in the synthesis of MPA-CdTe QDs conducted at ambient temperature.

Colloidal stability theory explains the role of $\mathrm{N}_{2} \mathrm{H}_{4} \cdot \mathrm{H}_{2} \mathrm{O}$ in the reaction medium. According to this theory, aqueous QDs exhibit an electrical double layer structure consisting of an inorganic core (1), a ligand (MPA) layer (2), an adsorbed layer (3), and a diffuse layer (4), as depicted in Figure 2. In this figure, the terms $\mathrm{Cd}(\mathrm{MPA}), \mathrm{Cd}(\mathrm{MPA})_{2}{ }^{2-}$, and $\mathrm{Cd}(\mathrm{MPA})_{3}{ }^{4}$ refer to the possible formation of $\mathrm{Cd}^{2+}$ complexes with the surface ligand MPA during the syntheses; the indexes correspond to the stoichiometric ratio among the two reagents; and $\mathrm{Cd}(\mathrm{MPA})\left(\mathrm{N}_{2} \mathrm{H}_{4}\right)$ refers to the possible complexation of $\mathrm{Cd}^{2+}$ ions with the thiol group of the ligand MPA and with the amino group of $\mathrm{N}_{2} \mathrm{H}_{4} \cdot \mathrm{H}_{2} \mathrm{O} \cdot{ }^{37,39}$ Moreover, various ions exist in the solution during the initial stage of the synthesis, namely $\mathrm{Cl}^{-}$(from $\mathrm{CdCl}_{2}$ ), the ionic Cd-surface ligand complexes, and $\mathrm{Na}^{+}$(from $\mathrm{Na}_{2} \mathrm{TeO}_{3}$ ).

For nanocrystals to grow, it is necessary that monomers diffuse from the solution to the surface of the nanocrystals via the diffusion layer. The diffusion layer thickness affects

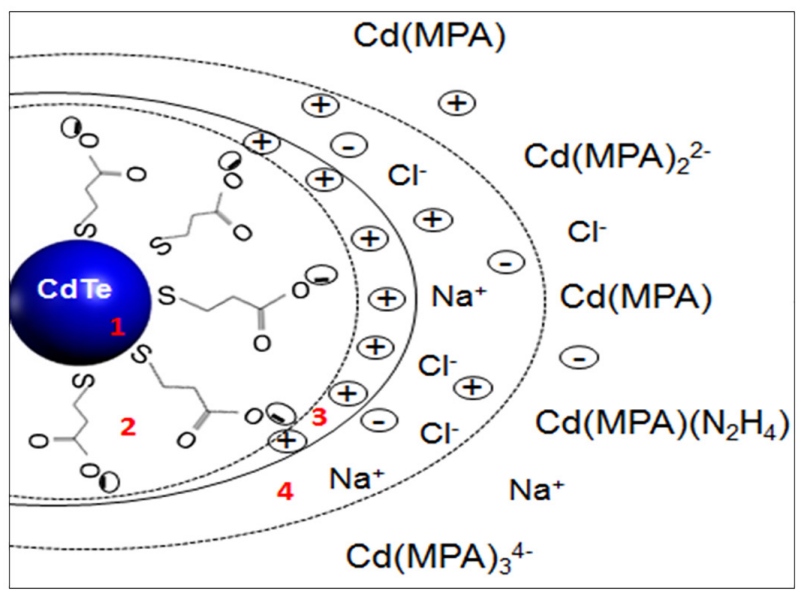

Figure 2. Schematic representation of the electrical double layer in the MPA-CdTe nanocrystals.

both the ability of monomers to diffuse to the surface of the nanocrystals and nanocrystal growth. Electrostatic considerations are fundamental during the development of QDs, higher ionic strength decreases electrostatic repulsion between monomers and facilitates aggregation of monomers and/or precursors, ${ }^{46,47}$ to form large nanocrystal nuclei. In the reaction medium, $\mathrm{N}_{2} \mathrm{H}_{4} \cdot \mathrm{H}_{2} \mathrm{O}$ serves as an electrolyte that raises the ionic strength, thereby reducing 
the thickness of the electrical double layer. This aids diffusion of the monomers and accelerates nanocrystal growth during the initial stage of the synthesis. ${ }^{47}$

The amino group in $\mathrm{N}_{2} \mathrm{H}_{4} \cdot \mathrm{H}_{2} \mathrm{O}$ has yet another function in the reaction medium: it competes with the surface ligand MPA for $\mathrm{Cd}^{2+}$ ions, to give $\mathrm{Cd}(\mathrm{MPA})\left(\mathrm{N}_{2} \mathrm{H}_{4}\right)$ complexes. This probably diminishes the charge on the $\mathrm{Cd}^{2+}$ monomers and facilitates their adhesion to the nanocrystals. However, it is noteworthy that the coordinative interaction between $\mathrm{Cd}^{2+}$ and the surface ligand MPA is stronger than the coordinative interaction between $\mathrm{Cd}^{2+}$ and $\mathrm{N}_{2} \mathrm{H}_{4} \cdot \mathrm{H}_{2} \mathrm{O}$, the logarithmic complexation constants are 8.8 and 2.25 , respectively. ${ }^{39}$ Consequently, higher $\mathrm{N}_{2} \mathrm{H}_{4} \cdot \mathrm{H}_{2} \mathrm{O}$ concentrations in the reaction medium are necessary to favor $\mathrm{Cd}^{2+} / \mathrm{MPA} / \mathrm{N}_{2} \mathrm{H}_{4} \cdot \mathrm{H}_{2} \mathrm{O}$ coordination, decrease the charge on the $\mathrm{Cd}^{2+}$ monomers, and promote nanocrystal growth. ${ }^{39}$

To verify how the $\mathrm{N}_{2} \mathrm{H}_{4} \cdot \mathrm{H}_{2} \mathrm{O}$ concentration affected the formation of MPA-CdTe QDs, the QDs were prepared in the presence of different $\mathrm{N}_{2} \mathrm{H}_{4} \cdot \mathrm{H}_{2} \mathrm{O}$ concentrations $(0,5.0$, $8.8,10.0$, and $\left.15.0 \mathrm{~mol} \mathrm{~L}^{-1}\right)$. Figure 3 presents the temporal evolution of the synthesis as a function of the PL band maximum recorded for the QDs. As mentioned previously, nanocrystals did not grow in the absence of $\mathrm{N}_{2} \mathrm{H}_{4} \cdot \mathrm{H}_{2} \mathrm{O}$ (see Figure 3a), but this amine accelerated nanocrystal growth in the initial stage of the synthesis; up to $2 \mathrm{~h}$ of synthesis, the graph was almost linear, as seen from the expanded spectrum in Figure 3b. In addition, increasing $\mathrm{N}_{2} \mathrm{H}_{4} \cdot \mathrm{H}_{2} \mathrm{O}$ concentration significantly displaced the bands toward longer wavelengths. ${ }^{37,39,41}$ For longer synthesis time, the PL intensity of $15.0 \mathrm{~mol} \mathrm{~L}^{-1}$ solution became lower than that of $10.0 \mathrm{~mol} \mathrm{~L}^{-1}$ solution, suggesting that for higher concentrations of $\mathrm{N}_{2} \mathrm{H}_{4} \cdot \mathrm{H}_{2} \mathrm{O}$ a saturation of the medium occurs, implying that the best concentration for CdTe nanocrystal growth is $10.0 \mathrm{~mol} \mathrm{~L}^{-1}$.

Figure 4 depicts the temporal evolution of the nanocrystal diameters during the synthesis of MPA-CdTe QDs in the presence of $\mathrm{N}_{2} \mathrm{H}_{4} \cdot \mathrm{H}_{2} \mathrm{O}$ at $5.0 \mathrm{~mol} \mathrm{~L}{ }^{-1}$. It can be seen that $\mathrm{N}_{2} \mathrm{H}_{4} \cdot \mathrm{H}_{2} \mathrm{O}$ accelerated nanocrystal growth. ${ }^{41}$ The UV-Vis absorption spectra of the nanocrystals (Figure 1c) and the equation described by Peng and co-workers ${ }^{48}$ were used to determine particle diameter. Peng and co-workers ${ }^{48}$ proposed that the nanocrystal size correlated with the absorbance wavelength $\left(\lambda_{\text {abs }}\right)$ in the case of CdTe, CdS, and CdSe QDs. For the MPA-CdTe QDs, this relation is expressed in equation 4 .

$$
\begin{aligned}
& \mathrm{D}=\left(9.8127 \times 10^{-7}\right) \lambda^{3}-\left(1.7147 \times 10^{-3}\right) \lambda^{2}+ \\
& 1.0064 \lambda-194.8
\end{aligned}
$$

where D corresponds to the nanocrystal diameter and $\lambda$ refers to the wavelength at which the MPA-CdTe QDs absorb. Indeed, Figure 4 shows that nanocrystal growth was faster in the initial stages of the synthesis.

Zeta potential measurements confirmed that the surface potential dropped with increasing $\mathrm{N}_{2} \mathrm{H}_{4} \cdot \mathrm{H}_{2} \mathrm{O}$ concentration (Table 2). This indicates that the addition of $\mathrm{N}_{2} \mathrm{H}_{4} \cdot \mathrm{H}_{2} \mathrm{O}$ to the reaction medium diminished the surface charge of the nanocrystals. ${ }^{39}$ According to the theory of colloidal stability, lower surface potentials reduce electrostatic repulsion between particles, which in turn decreases electrical double layer thickness. This facilitates ion adsorption and fusion and accelerates nanocrystal growth. ${ }^{37,43}$

The comparative method proposed by Williams et al. ${ }^{42}$ afforded $\theta_{\mathrm{f}}$ values for the MPA-CdTe QDs. The present

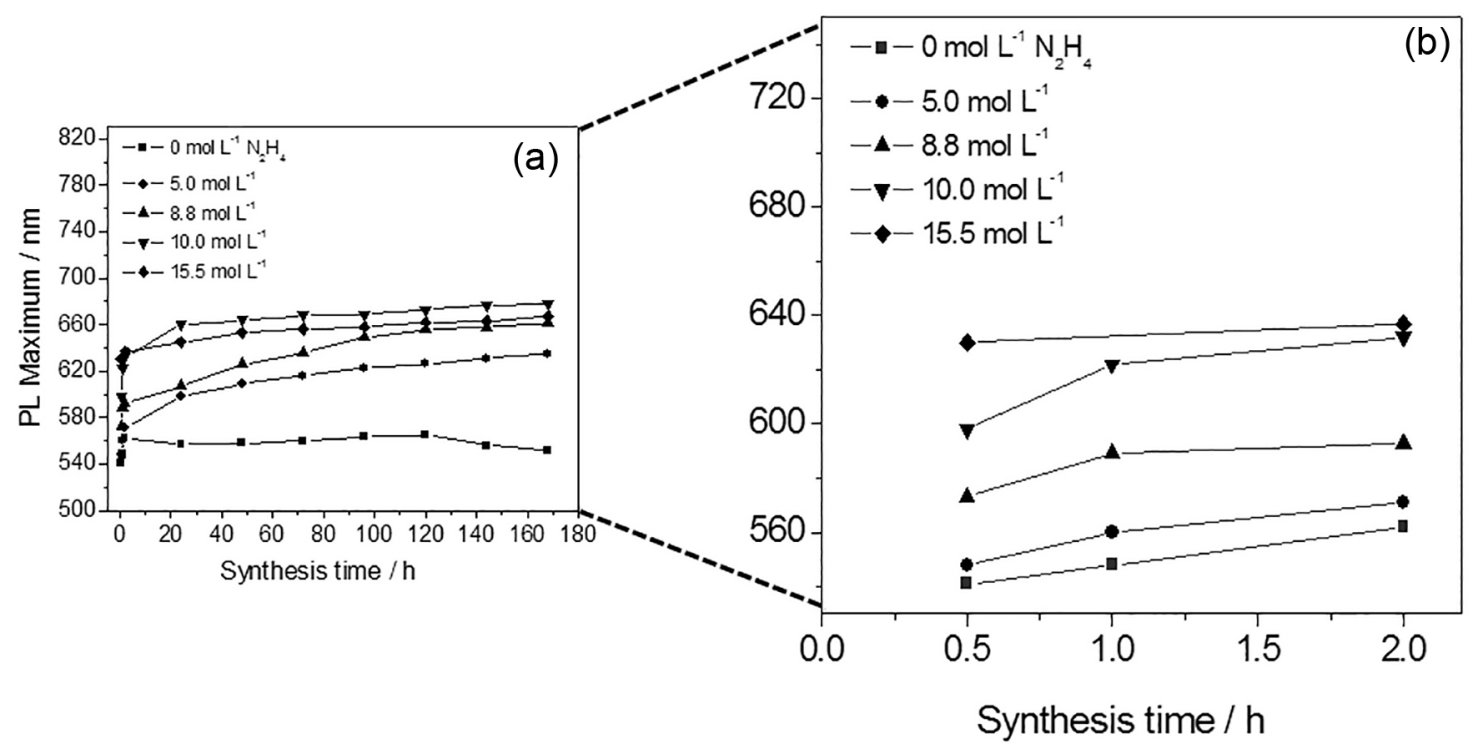

Figure 3. (a) Temporal evolution of the synthesis of the MPA-CdTe QDs as a function of the PL band maximum in the presence of different $\mathrm{N}_{2} \mathrm{H}_{4} \cdot \mathrm{H}_{2} \mathrm{O}$ concentrations; (b) expansion of the PL spectra between 0.5 and $2.0 \mathrm{~h}$ of synthesis. 


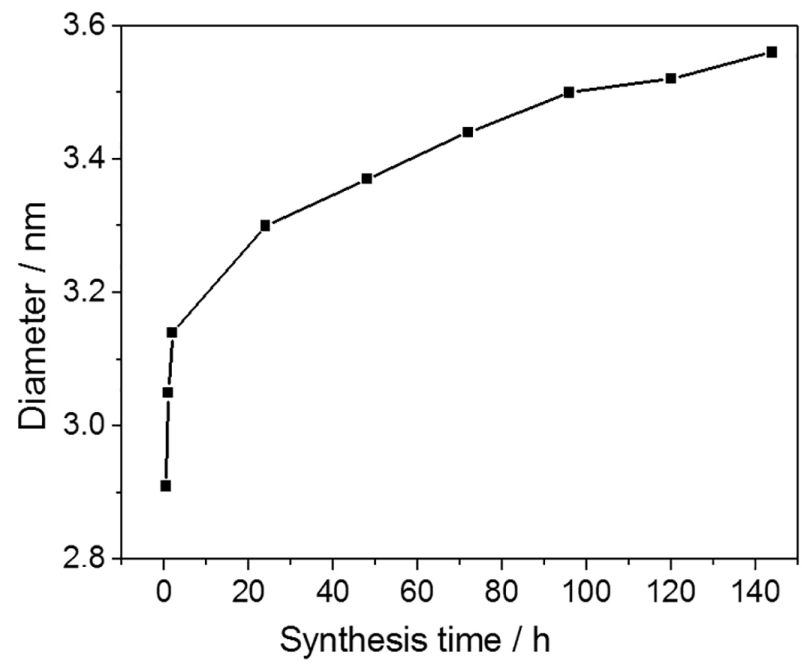

Figure 4. Temporal evolution of the nanocrystal diameter during the synthesis of the MPA-CdTe QDs in the presence of $\mathrm{N}_{2} \mathrm{H}_{4} \cdot \mathrm{H}_{2} \mathrm{O}$ at $5.0 \mathrm{~mol} \mathrm{~L}^{-1}$.

work used rhodamine 101 , with $\theta_{\mathrm{f}}=1.0$, as standard. Table 3 summarizes the quantum yields calculated for the MPA-CdTe QDs synthesized at $\mathrm{N}_{2} \mathrm{H}_{4} \cdot \mathrm{H}_{2} \mathrm{O}$ concentrations of 5.0 and $10.0 \mathrm{~mol} \mathrm{~L}^{-1}$. Figures $\mathrm{S} 1$ and $\mathrm{S} 2$ show the curves that allowed the determination of the PL quantum yields of the MPA-CdTe QDs and rhodamine. It can be observed that the curves show good correlation coefficients. It is important to show these curves because most papers do not describe how they determine the $\theta_{\mathrm{f}}$ nor show the quality of their analytical analysis of $\theta_{\mathrm{f}}$.

Table 2. Zeta potential measured at $\mathrm{pH}$ ca. 8 of the MPA-CdTe QDs synthesized in the presence of different $\mathrm{N}_{2} \mathrm{H}_{4} \cdot \mathrm{H}_{2} \mathrm{O}$ concentrations

\begin{tabular}{lc}
\hline $\mathrm{N}_{2} \mathrm{H}_{4} /\left(\mathrm{mol} \mathrm{L}^{-1}\right)$ & $\zeta$ Potential $/ \mathrm{mV}$ \\
\hline 0 & $-90.20 \pm 6.39$ \\
5.0 & $-26.80 \pm 2.58$ \\
8.8 & $-13.60 \pm 0.17$ \\
10.0 & $-5.43 \pm 0.67$ \\
15.0 & $-1.17 \pm 0.38$ \\
\hline
\end{tabular}

Analysis of the data recorded in the presence of $\mathrm{N}_{2} \mathrm{H}_{4} \cdot \mathrm{H}_{2} \mathrm{O}$ (Table 2) revealed that the quantum yields of the MPA-CdTe QDs increased up to $24 \mathrm{~h}$ of synthesis and decreased thereafter. This decrease was probably due to the defects that emerged on the nanocrystal surface as the nanocrystal diameter increased during the synthesis. The results also suggested that the use of lower $\mathrm{N}_{2} \mathrm{H}_{4} \cdot \mathrm{H}_{2} \mathrm{O}$ concentrations should afford MPA-CdTe QDs with superior optical characteristics and better PL quantum yields. The absence of heating and the lower crystallinity of the nanocrystals obtained during the synthesis of the MPA-CdTe QDs under ambient conditions should have led to smaller quantum yields than other literature results reported for QDs synthesized in aqueous medium. According to our methodology, the MPA-CdTe QDs obtained herein afforded higher quantum yields (27.5\%) than other nanocrystals reported in the literature (18\%) for this kind of synthesis method. ${ }^{38}$ Although the simplicity of the experimental setup used in the present work was noteworthy, it is possible to improve the experimental conditions of this fairly recently designed procedure further, to obtain even better QDs.

Table 3. PL quantum yields $\left(\theta_{\mathrm{f}}\right)$ determined as a function of the time evolution of the synthesis of the MPA-CdTe QDs in the presence of $\mathrm{N}_{2} \mathrm{H}_{4} \cdot \mathrm{H}_{2} \mathrm{O}$ at 5.0 and $10.0 \mathrm{~mol} \mathrm{~L}^{-1}$

\begin{tabular}{lcc}
\hline Synthesis time / h & $\begin{array}{c}\theta_{\mathrm{f}} \mathrm{N}_{2} \mathrm{H}_{4} \text { at } \\
5.0 \mathrm{~mol} \mathrm{~L}^{-1} / \%\end{array}$ & $\begin{array}{c}\theta_{\mathrm{f}} \mathrm{N}_{2} \mathrm{H}_{4} \text { at } \\
10.0 \mathrm{~mol} \mathrm{~L}^{-1} / \%\end{array}$ \\
\hline 1.0 & 19.4 & 4.4 \\
2.0 & 27.4 & 5.3 \\
24.0 & 27.5 & 6.3 \\
48.0 & 24.5 & 4.8 \\
72.0 & 8.5 & 40 \\
96.0 & 7.0 & 3.7 \\
120.0 & 3.8 & 3.3 \\
144.0 & 2.8 & 2.5 \\
\hline
\end{tabular}

It was observed that the PL lifetime behavior of the CdTe QDs is biexponential (see Figures S3 and S4), which is a typical feature of colloidal CdTe QDs. This biexponential behavior is due to the existence of different mechanisms of relaxation of the excited state to the ground state. The slower decaying component of PL can be associated with exciton recombination at the surface of the QDs, while the fast component can be attributed to the intrinsic recombination of the initially populated states of the core. ${ }^{48}$

A biexponential adjustment furnished the mean lifetimes of the MPA-CdTe QDs synthesized in the presence of $\mathrm{N}_{2} \mathrm{H}_{4} \cdot \mathrm{H}_{2} \mathrm{O}$ at 5.0 and $10.0 \mathrm{~mol} \mathrm{~L}^{-1}$ (Table S1). Figures S3 and $\mathrm{S} 4$ illustrate the biexponential decay curves that were used to determine the lifetimes of the MPA-CdTe QDs. According to Table S1, both $\mathrm{N}_{2} \mathrm{H}_{4} \cdot \mathrm{H}_{2} \mathrm{O}$ concentrations afforded QDs with the longest mean lifetime at $24 \mathrm{~h}$ of synthesis, but values decreased thereafter, as observed in the case of the quantum yield values (Table 3). Again, this decrease was probably associated with larger nanocrystal sizes, which may have affected the electron/hole pair recombination dynamics because a higher number of defects emerged on the nanocrystal surface. ${ }^{47,48}$ Interestingly, higher $\mathrm{N}_{2} \mathrm{H}_{4} \cdot \mathrm{H}_{2} \mathrm{O}$ concentration (10 $\mathrm{mol} \mathrm{L}^{-1}$ ) yielded longer lifetimes. Bearing in mind that the nanocrystals obtained at this higher $\mathrm{N}_{2} \mathrm{H}_{4} \cdot \mathrm{H}_{2} \mathrm{O}$ concentration had furnished smaller 
PL quantum yields (Table 3), non-radiative processes possibly occurred on the nanocrystal surface.
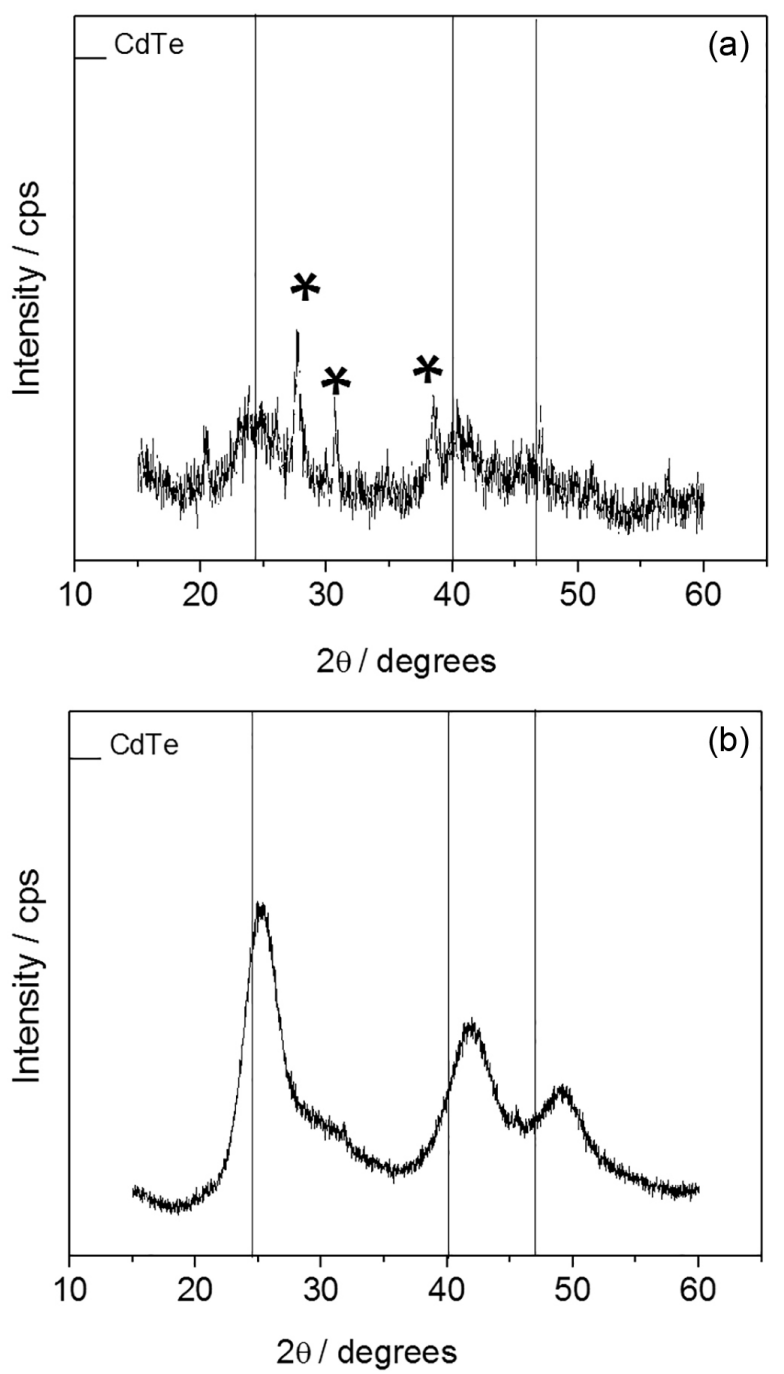

Figure 5. X-ray diffractograms of the MPA-CdTe QDs synthesized (a) in the presence of $\mathrm{N}_{2} \mathrm{H}_{4} \cdot \mathrm{H}_{2} \mathrm{O}$ and (b) by the traditional reflux method. ${ }^{28}$ The * refers to peaks of crystalline $\mathrm{NaCl}$.

Figures $5 \mathrm{a}$ and $5 \mathrm{~b}$ display the XRD pattern of the MPA-CdTe QDs synthesized under ambient conditions, in the presence of $\mathrm{N}_{2} \mathrm{H}_{4} \cdot \mathrm{H}_{2} \mathrm{O}$, and by the traditional reflux method, ${ }^{28}$ respectively. The nanocrystals synthesized herein presented diffraction peaks at approximately $24.5^{\circ}$, $40.5^{\circ}$, and $48.0^{\circ}(2 \theta)$ (Figure 5a), typical of a zinc blende crystalline structure. These peaks correspond to the (111), (220), and (311) planes of CdTe, respectively (JCPDS 65-1046), as marked by the solid vertical lines..$^{20}$ The peaks marked with an asterisk at approximately $27.3^{\circ}$ and $31.7^{\circ}$ in Figure 5a are due to the crystalline peaks of the $\mathrm{NaCl}$ structure; they referred to planes (111) and (200), respectively (JCPDS 05-0628). Indeed, $\mathrm{NaCl}$ was a reaction subproduct that originated from the tellurium and cadmium precursors, respectively. Purification by precipitation most likely failed to remove this subproduct entirely from the MPA-CdTe QDs.

On the basis of Figure 5a, the synthesis of the MPA-CdTe QDs at ambient temperature and in the presence of $\mathrm{N}_{2} \mathrm{H}_{4} \cdot \mathrm{H}_{2} \mathrm{O}$ was successfully achieved for the formation of $\mathrm{CdTe}$ nanocrystals. The fact that nanoparticle crystallization at ambient temperature is more difficult could account for the apparently lower crystallinity of the MPA-CdTe QDs obtained here (Figure 5a).

Figure S5 displays the STEM images registered for the MPA-CdTe QDs prepared in this work. Complementary images recorded in the bright-field and dark-field modes allowed for better visualization of the nanoparticles. The bright-field and dark-field micrographs afforded amplitude contrast and mass-thickness contrast imaging, respectively. The images confirmed the spherical morphology of the nanocrystals and their tendency to aggregate, as expected for QDs prepared in aqueous medium bearing MPA as the surface ligand. ${ }^{49}$

Synthesis of CdTe QDs in the presence of ethylenediamine

MPA-CdTe QDs were also prepared in the presence of ethylenediamine, $\mathrm{NH}_{2} \mathrm{CH}_{2} \mathrm{CH}_{2} \mathrm{NH}_{2}$, instead of $\mathrm{N}_{2} \mathrm{H}_{4} \cdot \mathrm{H}_{2} \mathrm{O}$, for comparison purposes. Again, the same simple experimental setup, ambient conditions, and MPA (as surface ligand) were employed. Figure 6 contains the PL spectra of the MPA-CdTe QDs prepared in the presence of $\mathrm{NH}_{2} \mathrm{CH}_{2} \mathrm{CH}_{2} \mathrm{NH}_{2}$. Figure $\mathrm{S} 6$ shows an emission photograph of these same QDs excited at $355 \mathrm{~nm}$. Like $\mathrm{N}_{2} \mathrm{H}_{4} \cdot \mathrm{H}_{2} \mathrm{O}, \mathrm{NH}_{2} \mathrm{CH}_{2} \mathrm{CH}_{2} \mathrm{NH}_{2}$ promoted nanocrystal growth at ambient temperature. The emission bands shifted toward longer wavelengths; nanocrystal emission varied from 500 to $549 \mathrm{~nm}$ in the electromagnetic spectrum.

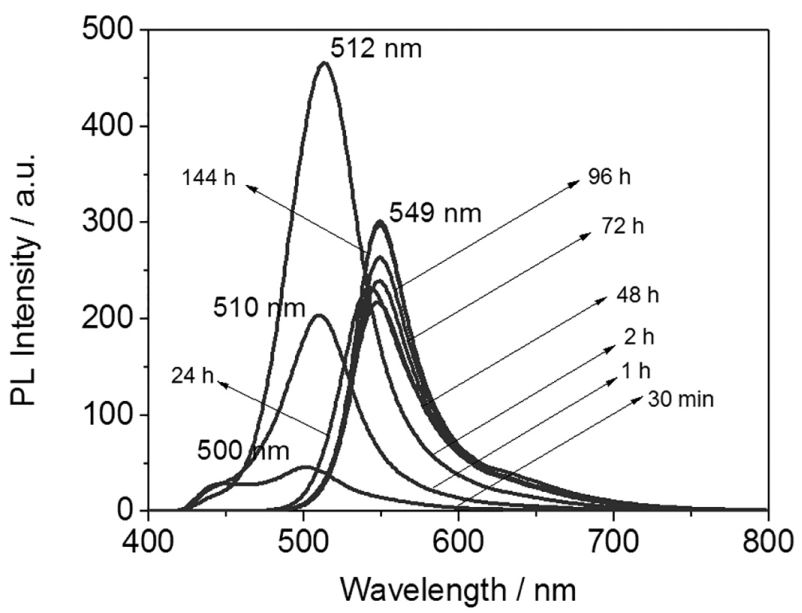

Figure 6. Evolution of the PL spectra of the MPA-CdTe QDs prepared in the presence of $\mathrm{NH}_{2} \mathrm{CH}_{2} \mathrm{CH}_{2} \mathrm{NH}_{2}$ at $5.0 \mathrm{~mol} \mathrm{~L}^{-1}$. 
However, the synthesis of QDs in the presence of $\mathrm{NH}_{2} \mathrm{CH}_{2} \mathrm{CH}_{2} \mathrm{NH}_{2}$ afforded nanocrystals that emitted in the green/yellow region only, as illustrated by the emission photograph in Figure S6.

Figure 7a illustrates the evolution of the synthesis of the MPA-CdTe QDs in the presence of the different amines as a function of the PL maximum of the QDs. $\mathrm{N}_{2} \mathrm{H}_{4} \cdot \mathrm{H}_{2} \mathrm{O}$ and $\mathrm{NH}_{2} \mathrm{CH}_{2} \mathrm{CH}_{2} \mathrm{NH}_{2}$ behaved similarly in the reaction medium. Both amines accelerated nanocrystal growth in the initial stage of the synthesis; the nanocrystal size varied only slightly thereafter. Compared with $\mathrm{N}_{2} \mathrm{H}_{4} \cdot \mathrm{H}_{2} \mathrm{O}$, the growth dynamics was slower in the presence of $\mathrm{NH}_{2} \mathrm{CH}_{2} \mathrm{CH}_{2} \mathrm{NH}_{2}-\mathrm{N}_{2} \mathrm{H}_{4} \cdot \mathrm{H}_{2} \mathrm{O}$ and $\mathrm{NH}_{2} \mathrm{CH}_{2} \mathrm{CH}_{2} \mathrm{NH}_{2}$ provided shifts of 88 and $49 \mathrm{~nm}$ in the electromagnetic spectrum, respectively. Figure $7 \mathrm{~b}$ shows that the diameters of the MPA-CdTe QDs synthesized in the presence of $\mathrm{N}_{2} \mathrm{H}_{4} \cdot \mathrm{H}_{2} \mathrm{O}$ were larger than the diameter of the MPA-CdTe QDs prepared in the presence of $\mathrm{NH}_{2} \mathrm{CH}_{2} \mathrm{CH}_{2} \mathrm{NH}_{2}$. This probably resulted from the different complexation constants of these amines with $\mathrm{Cd}^{2+}: \log K=2.25$ and 5.47 for $\mathrm{Cd}^{2+}-\mathrm{N}_{2} \mathrm{H}_{4}$ and $\mathrm{Cd}^{2+}-\mathrm{NH}_{2} \mathrm{CH}_{2} \mathrm{CH}_{2} \mathrm{NH}_{2}$, respectively. ${ }^{39} \mathrm{On}$ the basis of these constants, $\mathrm{NH}_{2} \mathrm{CH}_{2} \mathrm{CH}_{2} \mathrm{NH}_{2}$ bound to $\mathrm{Cd}^{2+}$ more strongly than $\mathrm{N}_{2} \mathrm{H}_{4} \cdot \mathrm{H}_{2} \mathrm{O}$ did. Consequently, $\mathrm{NH}_{2} \mathrm{CH}_{2} \mathrm{CH}_{2} \mathrm{NH}_{2}$ influenced complexation of $\mathrm{Cd}^{2+}$ with the thiol group of the MPA ligand to a larger extent and negatively affected the growth of the MPA-CdTe nanocrystals. Another reason for this behavior may be due to not all of the $\mathrm{Te}^{2-}$ ions being efficiently converted into nanoparticles, as the ethylenediamine possesses a less reducing character than hydrazine. Moreover, the carbon chain of $\mathrm{NH}_{2} \mathrm{CH}_{2} \mathrm{CH}_{2} \mathrm{NH}_{2}$ may also have impacted the growth dynamics of the QDs by generating a steric effect in the reaction medium. It should be noted that the nanocrystal sizes were calculated using equation 4.

\section{Synthesis of CdTe QDs in the presence of other electrolytes}

To test how other electrolytes worked in the synthesis of QDs at ambient temperature, MPA-CdTe QDs were prepared in the presence of $\mathrm{NaCl}$ or $\mathrm{NH}_{4} \mathrm{Cl}$, under ambient conditions; the experimental setup was the same as the one previously described for the syntheses of CdTe QDs carried out in the presence of $\mathrm{N}_{2} \mathrm{H}_{4} \cdot \mathrm{H}_{2} \mathrm{O}$ and $\mathrm{NH}_{2} \mathrm{CH}_{2} \mathrm{CH}_{2} \mathrm{NH}_{2}$. Figure S7a depicts the PL spectra obtained during the synthesis conducted in the presence of $\mathrm{NaCl}$; Figure $\mathrm{S} 7 \mathrm{~b}$ contains a photograph of the emission of the material synthesized in the presence of $\mathrm{NaCl}$, excited at $355 \mathrm{~nm}$. The PL spectra in Figure S7a demonstrated that CdTe nanocrystals did not arise in these conditions. The band at $446 \mathrm{~nm}$ was possibly due to complexation of $\mathrm{Cd}^{2+}$ with the MPA surface ligand or even due to the Raman spectrum
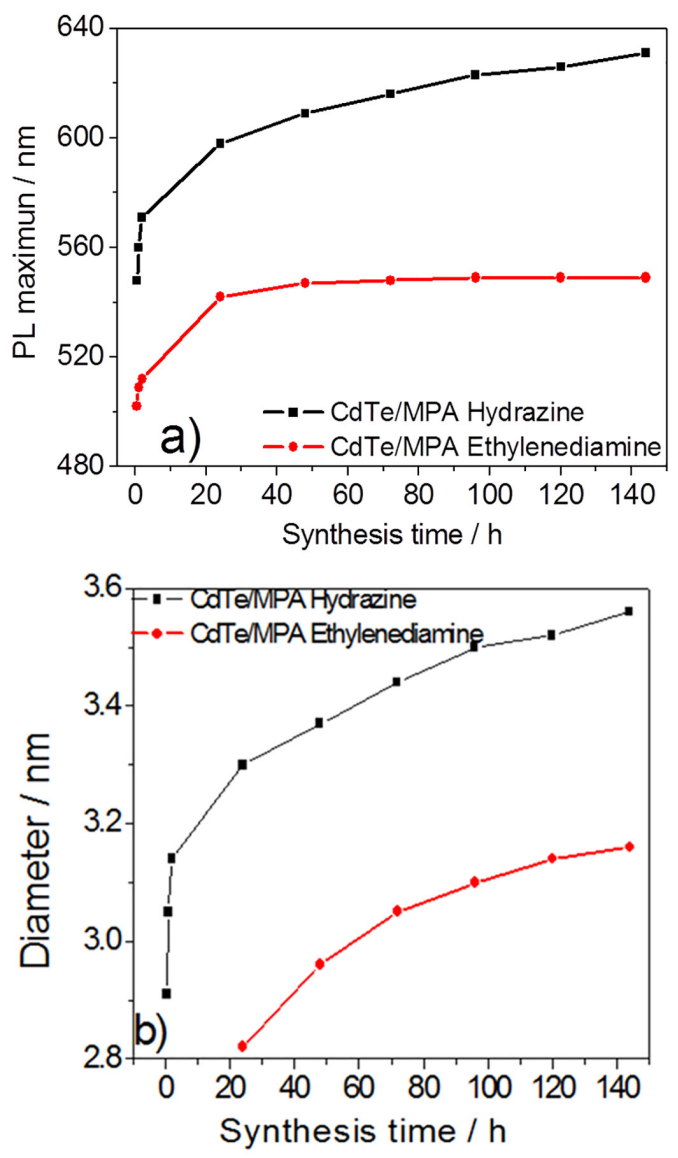

Figure 7. Temporal evolution of the synthesis of the MPA-CdTe QDs in the presence of different amines at $5.0 \mathrm{~mol} \mathrm{~L}^{-1}$ in terms of (a) the PL maximum of the QDs and (b) of the nanocrystal diameter.

of water. In addition, Figure S7b did not show any PL emission, thereby confirming the absence of nanocrystal growth.

These results led to the conclusion that $\mathrm{N}_{2} \mathrm{H}_{4} \cdot \mathrm{H}_{2} \mathrm{O}$ and $\mathrm{NH}_{2} \mathrm{CH}_{2} \mathrm{CH}_{2} \mathrm{NH}_{2}$ not only acted as electrolytes in the reaction medium, but they also competed with the surface ligand for $\mathrm{Cd}^{2+}$, to promote nanocrystal growth. Hence, we decided to conduct the synthesis of MPA-CdTe QDs in the presence of the electrolyte $\mathrm{NH}_{4} \mathrm{Cl}$, which bears an amine group, and recorded the PL spectra of the resulting material (Figure 8).

The set of spectra in Figure 8 revealed that the emission bands shifted slightly toward shorter wavelength during the synthesis, from 551 to $538 \mathrm{~nm}$. MPA-CdTe QDs were produced in the reaction medium, and they emitted in the green/yellow region. However, the QDs were not stable after $24 \mathrm{~h}$ of reaction, as shown by the PL spectrum recorded at $48 \mathrm{~h}$ of synthesis, where a typical band due to the Raman spectrum of water appears. Figure S8 in the Supplementary Information presents emission photographs of the MPA-CdTe QDs obtained in the presence of $\mathrm{NH}_{4} \mathrm{Cl}$, excited at $355 \mathrm{~nm}$. This figure 


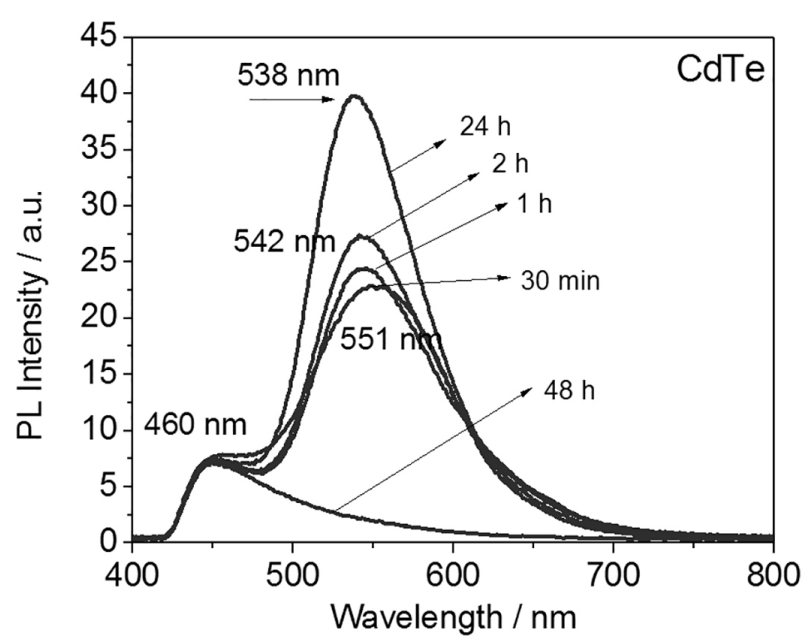

Figure 8. PL spectra of the MPA-CdTe QDs synthesized in the presence of $\mathrm{NH}_{4} \mathrm{Cl}$ at $5.0 \mathrm{~mol} \mathrm{~L}^{-1}$.

demonstrates that the QDs lost luminescence after $48 \mathrm{~h}$ of synthesis. $\mathrm{NH}_{4} \mathrm{Cl}$ probably did not supply enough ionic strength to act as an electrolyte in the electrical double layer, nor did the ammonium group of this salt promote satisfactory nanocrystal growth. These results attested to the ability and efficiency of amines, especially $\mathrm{N}_{2} \mathrm{H}_{4}$. $\mathrm{H}_{2} \mathrm{O}$, to promote the growth of MPA-CdTe QDs under ambient conditions, highlighting the importance of complexation of $\mathrm{Cd}^{2+}$ ions to assure at least some degree of crystallization during the QDs' nucleation.

Treatment of hydrazine solutions for later discharge into the environment

Before their discharge into the environment, it was necessary to decompose the $\mathrm{N}_{2} \mathrm{H}_{4} \cdot \mathrm{H}_{2} \mathrm{O}$ present in the solutions with $\mathrm{NaOCl}{ }^{43,44}$ According to reaction 5, $\mathrm{NaOCl}$ oxidizes $\mathrm{N}_{2} \mathrm{H}_{4} \cdot \mathrm{H}_{2} \mathrm{O}$, with consequent release of nitrogen.

$\mathrm{N}_{2} \mathrm{H}_{4(\mathrm{aq})}+2 \mathrm{NaOCl}_{(\mathrm{aq})} \rightarrow \mathrm{N}_{2(\mathrm{~g})}+2 \mathrm{NaOCl}_{(\mathrm{aq})}+2 \mathrm{H}_{2} \mathrm{O}_{(\mathrm{l})}$

$\mathrm{N}_{2} \mathrm{H}_{4} \cdot \mathrm{H}_{2} \mathrm{O}$ decomposition by $\mathrm{NaOCl}$ is fast, simple, and inexpensive. ${ }^{43}$ After the decomposition reaction, it was essential to acidify the medium with sulfuric acid to achieve a pH between 5 and 10, which is ideal for discharge. Figure $\mathrm{S} 9$ shows the absorption spectra of pure $\mathrm{N}_{2} \mathrm{H}_{4} \cdot \mathrm{H}_{2} \mathrm{O}$, of the sample to be discharged, and of the samples obtained after $\mathrm{N}_{2} \mathrm{H}_{4} \cdot \mathrm{H}_{2} \mathrm{O}$ decomposition. The band at approximately $800 \mathrm{~nm}$ is due to $\mathrm{N}_{2} \mathrm{H}_{4} \cdot \mathrm{H}_{2} \mathrm{O}$. It appeared in the spectra represented in black (pure $\mathrm{N}_{2} \mathrm{H}_{4} \cdot \mathrm{H}_{2} \mathrm{O}$ ) and green (sample to be discharged), but the samples treated with $\mathrm{NaOCl}$ did not display this band, which proved that the treatment method effectively consumed all of the $\mathrm{N}_{2} \mathrm{H}_{4} \cdot \mathrm{H}_{2} \mathrm{O}$ present in the reaction medium.

\section{Conclusions}

This work dealt with the synthesis of CdTe QDs via colloidal chemistry in aqueous medium, under ambient conditions, in the presence of hydrazine. This amine played two fundamental roles: it weakened the electrostatic repulsion between the nanoparticles and competed with the surface ligand for coordination to cadmium ions. Varying reaction times and hydrazine concentrations afforded $\mathrm{CdTe}$ QDs of different sizes. In the absence of hydrazine, the synthesis of QDs under ambient conditions did not favor nanocrystal growth. The PL quantum yields of the QDs were higher than the values reported in the literature for this kind of synthesis. A PL quantum yield of $27.5 \%$ was found.

Substitution of hydrazine for ethylenediamine in the reaction medium showed that these amines behaved similarly, but hydrazine promoted faster nanocrystal growth and better PL emission, which ranged from green to red. This phenomenon was due to the different complexation constants between these amines and cadmium ions. Therefore, we can design the size growth rate of CdTe QDs at room temperature by choosing the amine used to complex the cadmium ion at the onset of synthesis.

The use of other electrolytes instead of amines in the reaction medium showed that sodium chloride, which bears no amino group, did not favor nanocrystal growth, whereas ammonium chloride, which has a very low complex constant formation with $\mathrm{Cd}^{2+}$ ions, promoted nanocrystal growth up to $24 \mathrm{~h}$ of synthesis but with not enough cohesion to make the QDs stable.

\section{Supplementary Information}

Supplementary data are available free of charge at http://jbcs.sbq.org.br as a PDF file.

\section{Acknowledgments}

The authors acknowledge CAPES, CNPq, FINEP, and FAPEMIG for financial support.

\section{References}

1. Chang, J.; Waclawik, E. R.; RSC Adv. 2014, 4, 23505.

2. Silva, F. O.; Viol, L. C. S.; Ferreira, D. L.; Alves, J. L. A.; Schiavon, M. A.; Quim. Nova 2010, 9, 1933.

3. Ekimov, A. I.; Onuschenko, A. A.; Semiconductors 1982, 16, 1215.

4. Nozic, A. J.; Micic, O. I.; MRS Bull. 1998, 23, 24.

5. Bera, D.; Qian, L.; Tseng, T. K.; Holloway, P. H.; Materials 2010, 3, 2260. 
6. Al-Hosiny, N.; Abdallah, S.; Badawi, A.; Easawi, K.; Talaat, H.; Mater. Sci. Semicond. Process. 2014, 26, 238.

7. Kouhnavard, M.; Ikeda, S.; Ludin, N. A.; Ahmad Khairudin, N. B.; Ghaffari, B. V.; Mat-Teridi, M. A.; Ibrahim, M. A.; Sepeai, S.; Sopian, K.; Renewable Sustainable Energy Rev. 2014, 37, 397.

8. Ippen, C.; Greco, T.; Kim, J.; Oh, M. S.; Han, C. J.; Wedel, A.; Org. Electron. 2014, 15, 126.

9. Lin, Y.; Zhang, Y.; Zhao, J.; Gu, P.; Bi, K.; Zhang, Q.; Chu, H.; Zhang, T.; Cui, T.; Wang, Y.; Zhao, J.; Yu, W. W.; Particuology 2014, 15, 90 .

10. Samadi-Maybodi, A.; Abbasi, F.; Akhoondi, R.; Colloids Surf., A 2014, 447, 111.

11. Mansur, A. A. P.; Mansur, H. S.; Ramanery, F. P.; Oliveira, L. C.; Souza, P. P.; Appl. Catal., B 2014, 158, 269.

12. Tenório, D. P.; Andrade, C. G.; Cabral Filho, P. E.; Sabino, C. P.; Kato, I. K.; Carvalho Jr., L. B.; Alves Jr., S.; Ribeiro, M. S.; Fontes, A.; Santos, B. S.; J. Photochem. Photobiol., B 2015, 142, 237.

13. Smith, A. M.; Nie, S.; Analyst 2004, 129, 672.

14. Maquire, C. M.; Mahfoud, O. K.; Rakovich, T.; Gerard, V. A.; Prina-Mello, A.; Gun'Ko, Y.; Volkov, Y.; Nanomedicine 2014, $10,1853$.

15. Li, X.; Deng, D.; Xue, J.; Qu, L.; Achilefu, S.; Gu, Y.; Biosens. Bioelectron. 2014, 61, 512.

16. Mansur, A. A. P.; Saliba, J. B.; Mansur, H. S.; Colloids Surf., B 2013, 111, 60 .

17. Chatterjee, K.; Sarkar, S.; Rao, K. J.; Paria, S.; Adv. Colloid Interface Sci. 2014, 209, 8.

18. Song, Y.; Li, Y.; Liu, Z.; Liu, L.; Wang, X.; Su, X.; Ma, Q.; Biosens. Bioelectron. 2014, 61, 9.

19. Beloglazova, N. V.; Speranskaya, E. S.; Wu, A.; Wang, Z.; Sanders, M.; Goftman, V. V.; Zhang, D.; Goryacheva, I. Yu.; De Saeger, S.; Biosens. Bioelectron. 2014, 62, 59.

20. Rogach, A. L.; Semiconductor Nanocrystal Quantum Dots: Synthesis, Assembly, Spectroscopy and Application; SpringerVerlag/Wien: Vienna, Austria, 2008.

21. Gaponik, N.; Talapin, D. V.; Rogach, A. L.; Hoppe, K.; Shevchenko, E. V.; Komowski, A.; Eychmuller, A.; Weller, H.; J. Phys. Chem. B 2002, 106, 7177.

22. Lamer, V. K.; Dinegar, R. H.; J. Am. Chem. Soc. 1950, 72, 4847.

23. Zhou, D.; Han, J.; Liu, Y.; Liu, M.; Zhang, X.; Zhang, H.; Yang, B.; J. Phys. Chem. C 2010, 114, 22487.

24. Murray, C. B.; Norris, D. J.; Bawendi, M. G.; J. Am. Chem. Soc. 1993, 115, 8706.

25. Talapin, D. V.; Rogach, A. L.; Kornowski, A.; Haase, M.; Weller, H.; Nano Lett. 2001, 1, 207.

26. Peng, Z. A.; Peng, X.; J. Am. Chem. Soc. 2001, 123, 183.

27. Rogach, A. L.; Katsikas, L.; Kornowski, A.; Su, D.; Eychmuller, A.; Weller, H.; Bunsen-Ges. Phys. Chem., Ber. 1996, 100, 1772.
28. Silva, F. O.; Carvalho, M. S.; Mendonça, R.; Macedo, W. A.; Balzuweit, K.; Reis, P.; Schiavon, M. A.; Nanoscale Res. Lett. 2012, 7, 536.

29. Weiss, E. A.; Acc. Chem. Res. 2013, 46, 2607.

30. Hines, D. A.; Kamat, P. V.; ACS Appl. Mater. Interfaces 2014, 6,3041 .

31. Vale, B. R. C.; Vieira, K. O.; Sousa, J. C. L.; Ferrari, J. L.; Schiavon, M. A.; Quim. Nova 2015, 38, 22.

32. Jothi, N. S. N.; Joshi, A. G.; Vijay, R. J.; Muthuvinayagam, A.; Sagayaraj, P.; Mater. Chem. Phys. 2013, 138, 186.

33. Wang, J.; Han, H.; J. Colloid Interface Sci. 2010, 351, 83.

34. Shahid, R.; Toprak, M. S.; Munhammed, M.; J. Solid State Chem. 2012, 187, 130.

35. Shi, J. J.; Wang, S.; He, T. T.; Abdel-Halim, E. S.; Zhu, J. J.; Ultrason. Sonochem. 2014, 21, 493.

36. Ribeiro, R. T.; Dias, J. M. M.; Pereira, G. A.; Freitas, D. V.; Monteiro, M.; Cabral Filho, P. E.; Raele, R. A.; Fontes, A.; Navarro, M.; Santos, B. S.; Green Chem. 2013, 15, 1061.

37. Han, J.; Zhang, H.; Sun, H.; Zhou, D.; Yang, B.; Phys. Chem. Chem. Phys. 2010, 12, 332.

38. Zhou, D.; Lin, M.; Chen, Z.; Sun, H.; Zhang, H.; Sun, H.; Yang, B.; Chem. Mater. 2011, 23, 4857.

39. Han, J.; Luo, X.; Zhou, D.; Sun, H.; Zhang, H.; Yang, B.; J. Phys. Chem. C 2010, 114, 6418.

40. Shen, Q.; Liu, Y.; Yu, X.; Liu, X.; Zou, M.; Li, J.; Zhou, J.; ACS Nano 2012, 7, 1250046.

41. Tan, J.; Liang, Y.; Wan, J.; Chen, J.; Sun, B.; Shao, L.; New J. Chem. 2015, 39, 4488.

42. Williams, A. T. R.; Winfield, S. A.; Miller, J. N.; Analyst 1983, 108, 1067.

43. Choudhary, G.; Hansen, H.; Chemosphere 1998, 37, 801.

44. Carlsen, L.; Kenesova, O. A.; Batyrbekova, S. E.; Chemosphere 2007, 67, 1108.

45. Miranda, M. S.; Algarra, M.; Jiménez-Jiménez, J.; RodriguezCastellón, E.; Campos, B. B.; Silva, J. C. G. E.; J. Lumin. 2013, $134,408$.

46. Zhang, H.; Liu, Y.; Wang, C.; Zhang, J.; Sun, H.; Li, M.; Yang, M.; ChemPhysChem 2008, 9, 1309.

47. Hiemenz, F. P. C.; Rajagopalan, R.; Principles of Colloid and Surface Chemistry, $3^{\text {rd }}$ ed.; CRC Press: New York, USA, 1997.

48. Wang, X.; Qu, L.; Zhang, J.; Peng, X.; Xiao, M.; Nano Lett. 2003, 3, 1103.

49. Viol, L. C. S.; Raphael, E.; Bettini, J.; Ferrari, J. L.; Schiavon, M. A.; Part. Part. Syst. Charact. 2014, 31, 1084.

Submitted: July 14, 2016

Published online: October 14, 2016

FAPESP has sponsored the publication of this article. 